\title{
Axitinib for the Management of Metastatic Renal Cell Carcinoma
}

\author{
Bernard Escudier ${ }^{1}$ and Martin Gore ${ }^{2}$ \\ 1 Institut Gustave Roussy, Villejuif, France \\ 2 Royal Marsden Hospital, Institute of Cancer Research, London, UK
}

\section{Contents}

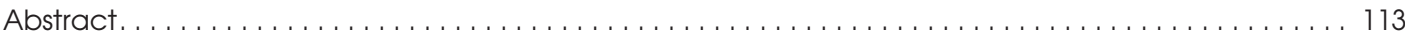

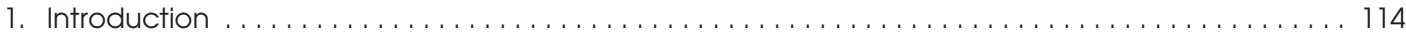

2. Mode of Action and Rationale ....................................... 115

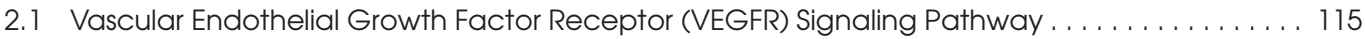

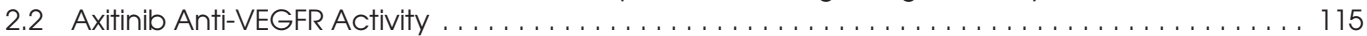

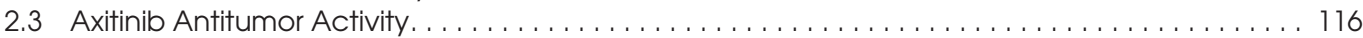

3. Pharmacokinetics/Pharmacodynamics .................................. 116

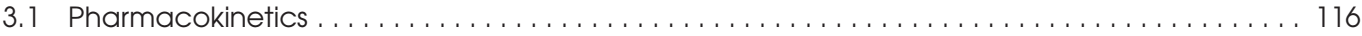

3.2 Pharmacodynamics.............................................. 118

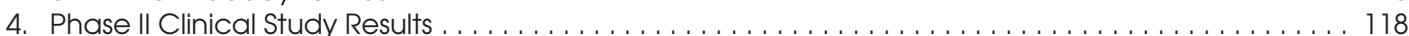

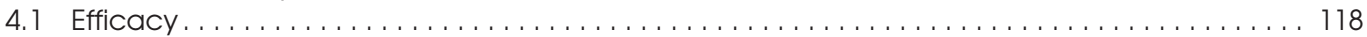

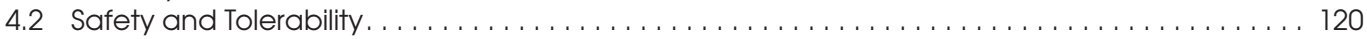

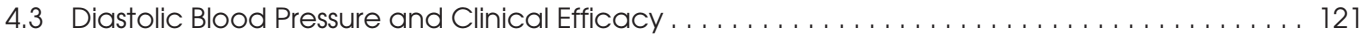

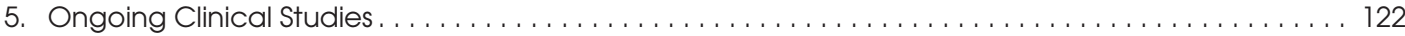

5.1 Ongoing Phase II Clinical Study: The AGILE 1046 Trial . . . . . . . . . . . . . . . . . . . . . . . . . 122

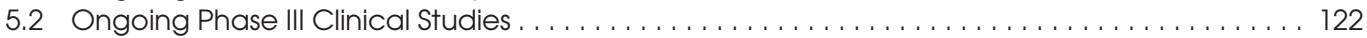

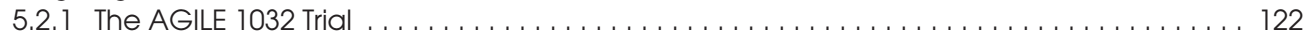

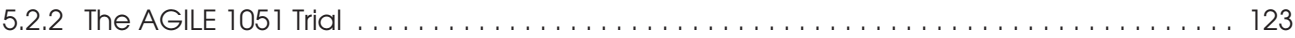

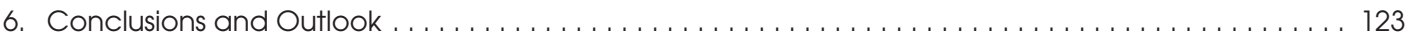

In recent years, targeted agents have changed the treatment landscape for patients with advanced renal cell carcinoma (RCC), greatly improving treatment outcomes. Several targeted agents are now licensed for the treatment of metastatic RCC (mRCC), and a number of new agents are under investigation. Axitinib, a small molecule indazole derivative is an oral, potent multitargeted tyrosine kinase receptor inhibitor, which selectively inhibits vascular endothelial growth factor receptors (VEGFR)-1, -2, and -3 at subnanomolar concentrations, in vitro. In various nonclinical models, axitinib has demonstrated in vivo target modulation and antiangiogenesis. In pharmacokinetic studies, axitinib administered orally with food at the proposed regimen of $5 \mathrm{mg}$ twice daily continuous daily dosing, is rapidly absorbed, reaching peak concentrations within 2-6 hours. Axitinib is metabolized primarily in the liver via the cytochrome P450 (CYP) system with less than $1 \%$ of the administered drug passing unchanged in the urine. The pharmacokinetics of axitinib do not appear to be altered by coadministered 
chemotherapies, and antacids do not have a clinically significant effect. However, coadministration with CYP3A4 and 1A2 inducers is contraindicated. In addition, proton pump inhibitors reduce the rate of axitinib absorption. Increased axitinib exposure is associated with higher efficacy indicated by decreased tumor perfusion and volume. In three phase II clinical trials in patients with advanced RCC previously treated with cytokines, chemotherapy or targeted agents, axitinib has demonstrated antitumor activity with a favorable noncumulative toxicity profile. In one study of Western patients with cytokinerefractory $\mathrm{mRCC}$, an objective response rate (ORR) of $44.2 \%$ (95\% CI 30.5, 58.7) was achieved. The median time to progression was 15.7 months $(95 \% \mathrm{CI}$ $8.4,23.4$ ) and the median overall survival (OS) was 29.9 months (95\% CI 20.3, not estimable). In the second study of patients with sorafenib-refractory mRCC, ORR was $22.6 \%$ (95\% CI 12.9, 35.0). The median progression-free survival (PFS) was 7.4 months $(95 \%$ CI 6.7, 11.0) and a median OS of 13.6 months $(95 \%$ CI 8.4, 18.8) was achieved. Results from the third study in Japanese patients with cytokine-refractory $\mathrm{mRCC}$ reported an ORR of 55\% and median PFS of 12.9 months (95\% CI 9.8, 15.6).

In the three studies, the most common adverse events reported were fatigue, hypertension, hand-foot syndrome (HFS), and gastrointestinal toxicity, which were generally manageable with standard medical intervention. Of note, the incidence of HFS and proteinuria in the Japanese study was higher than that reported in the Western study in cytokine-refractory mRCC patients.

An observed association between diastolic blood pressure $\geq 90 \mathrm{mmHg}$ and increased efficacy suggests potential use as a prognostic biomarker. However, this requires further investigation. Two randomized phase III clinical trials are ongoing to determine the efficacy of axitinib in patients with $\mathrm{mRCC}$ in the first- and second-line setting. These results will help to determine the place of axitinib in the mRCC treatment algorithm.

\section{Introduction}

Renal cell carcinoma (RCC) is the most common form of kidney cancer. It is diagnosed in more than 200000 patients worldwide every year and accounts for approximately 100000 deaths annually. ${ }^{[1,2]}$ In the last half-century, the incidence of RCC has increased; in the US alone, there has been a $126 \%$ increase in incidence and a $36.5 \%$ increase in mortality since 1950 , with a corresponding increase in annual mortality, possibly due to the continuing development of advanced screening techniques. ${ }^{[3,4]}$

Most cases of RCC are of clear cell histology, which is often associated with mutations of the Von Hippel-Lindau (VHL) tumor suppressor gene, resulting in an increased transcription of several hypoxia-inducible genes including vas- cular endothelial growth factor (VEGF), a potent signaling molecule involved in inhibition of dendritic cell maturation, tumor cell apoptosis, and promotion of tumor angiogenesis. ${ }^{[5-8]}$ The incidence of metastatic RCC ( $\mathrm{mRCC}$ ) is highest in developed regions, such as the US and Europe. ${ }^{[9]}$ mRCC is highly resistant to conventional treatments, with a 5-year survival rate with stage IV disease (of which one-third of patients present with at initial diagnosis) of just $0-10 \% .{ }^{[9]}$ Additionally, recurrence develops in approximately $20-40 \%$ of patients treated for a localized tumor..$^{[9,10]}$

Until recently, standard treatment for $\mathrm{mRCC}$ has consisted of immunotherapy with either interleukin-2 (IL-2) or interferon- $\alpha$ (IFN $\alpha$ ), both of which are associated with overall response rates (ORRs) of 5-20\%, and significant clinical toxicities. ${ }^{[1-15]}$ In randomized controlled trials, 
IFN $\alpha$ has been associated with a median overall survival (OS) of $12-19$ months, ${ }^{[16-18]}$ and highdose IL-2 can result in disease cure in $5-10 \%$ of patients. ${ }^{[19]}$ Additionally, treatment options were scarce for those patients who progressed on cytokine therapy.

In recent years, targeted agents have changed the treatment landscape for patients with advanced RCC, greatly improving treatment outcomes. Several targeted agents are now licensed for the treatment of mRCC, including the multitargeted tyrosine kinase inhibitors sunitinib, sorafenib and pazopanib; the mammalian target inhibitor of rapamycin (mTOR) kinase inhibitors temsirolimus and everolimus; and the VEGF monoclonal antibody bevacizumab in combination with IFN $\alpha .{ }^{[20-25]}$

ORRs of $26-46 \%$ have been reported with these targeted agents in patients with mRCC. ${ }^{[20,23,25]}$ Median progression-free survival (PFS) of 6-11 months has been achieved in treatment-naïve patients, ${ }^{[20,22,23,25]}$ and $5-6$ months in previously treated patients. ${ }^{[21,24]}$ Targeted agents have also been associated with a significantly increased median OS of up to 18 months in previously treated patients, ${ }^{[21,24]}$ while in treatment-naïve patients, median OS greater than 2 years has been attained with sunitinib. ${ }^{[26]}$ Targeted agents have also shown efficacy in previously untreated patients with poor prognosis, with the mTOR inhibitor temsirolimus improving median OS by $49 \%$ compared with IFN $\alpha$ alone. ${ }^{[22]}$

A number of second-generation targeted therapies are on the horizon, including axitinib, a potent and selective inhibitor of VEGF receptor tyrosine kinases (VEGF RTK)-1, -2 , and -3 that has shown substantial anticancer activity in phase II trials in patients with RCC. This article discusses the preclinical and clinical data for axitinib for the management of RCC.

\section{Mode of Action and Rationale}

\section{1 Vascular Endothelial Growth Factor Receptor (VEGFR) Signaling Pathway}

Among other factors, the VEGFR signaling pathway plays a key role in the pathogenesis and progression of several tumor types as a pivotal mediator of tumor angiogenesis. ${ }^{[27,28]}$ VEGFR-1, -2 , and -3 are expressed in vascular sprouts, although VEGFR-3 is found primarily in the lymphatic system. ${ }^{[28-31]}$ Indeed, signaling via the VEGFR family plays a role in regulating all three key tumor processes: growth, vascular angiogenesis, and metastatic spread. ${ }^{[27]}$ VEGFR-1 is involved in angiogenesis and tumor growth; VEGFR-2 is involved in endothelial cell proliferation, migration and survival, and angiogenesis; and VEGFR-3 is involved in lymphangiogenesis. ${ }^{[28,30]}$

\subsection{Axitinib Anti-VEGFR Activity}

Axitinib, a small molecule indazole derivative, is an oral, potent, and highly selective inhibitor of VEGFR-1, -2, and -3. The structure-based drug design of axitinib allows strategic optimization of critical binding elements, with the tight fit of axitinib into the 'deep pocket' conformation of the kinase domain of VEGFRs resulting in high potency and selectivity (figure 1). ${ }^{[32]}$

In vitro, axitinib inhibits VEGFR-1, -2, and -3 autophosphorylation at picomolar concentrations, consistent with its potent and highly selective activity against these receptors. Indeed, the half maximal inhibitory concentration $\left(\mathrm{IC}_{50}\right)$ for axitinib is 10-fold lower for the VEGF family receptors than for RTKs of other family receptors. ${ }^{[32]}$ The $\mathrm{IC}_{50}$ for axitinib is also lower than other RTK inhibitors for most of the targets of interest (table I). ${ }^{[33-38]}$ The relative potencies of axitinib

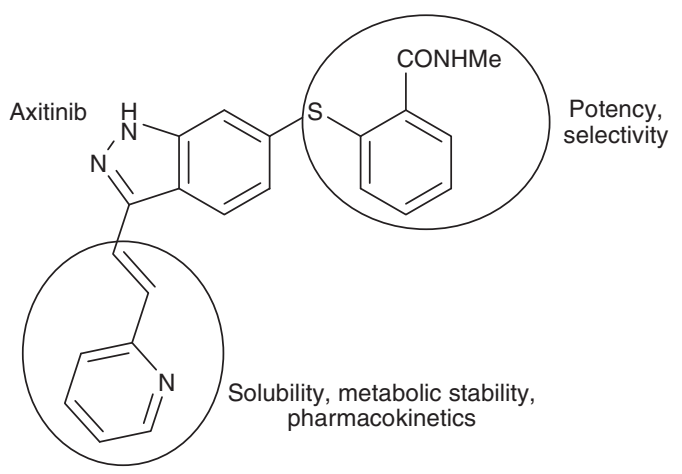

Fig. 1. Axitinib drug design. Reproduced from Hu-Lowe et al., ${ }^{[32]}$ with permission. 
Table I. $I C_{50}$ for selected targeted agents. Reproduced from Bellmunt et al.,, ${ }^{[3]}$ with permission

\begin{tabular}{|c|c|c|c|c|}
\hline \multirow[t]{2}{*}{ Target } & \multicolumn{4}{|l|}{$\mathrm{IC}_{50}(\mathrm{nM})$} \\
\hline & sunitinib $^{[34,35]}$ & sorafenib $^{[35-37]}$ & pazopanib $[35,38]$ & axitinib $^{[32]}$ \\
\hline VEGFR-1 & 2 & NR & 10 & $0.1^{\mathrm{a}}$ \\
\hline VEGFR-2 & 10 & 90 & 30 & 0.2 \\
\hline VEGFR-3 & 17 & 20 & 47 & $0.1-0.3$ \\
\hline PDGFR- $\beta$ & 8 & 57 & 84 & 1.6 \\
\hline EGFR & 880 & 58 & NR & NR \\
\hline c-KIT & 10 & 68 & 74 & 1.7 \\
\hline FGF-1R & 880 & 580 & 14 & 231 \\
\hline FLT-3 & 14 & 58 & NR & $>1000$ \\
\hline Raf-1 & NR & 6 & NR & NR \\
\hline CSF-1R & 100 & NR & NR & 73 \\
\hline
\end{tabular}

a Converted from value obtained in the presence of $2.3 \%$ bovine serum albumin.

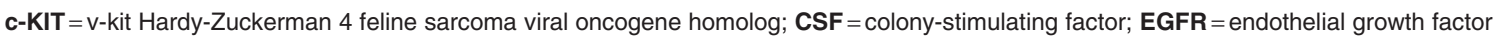
receptor; FGF=fibroblast growth factor; $\mathbf{F L T}=\mathrm{FMS}$-like tyrosine kinase; $\mathbf{I C}_{\mathbf{5 0}}=$ concentration of a drug that is required to achieve $50 \%$ inhibition of the enzyme in a biochemical assay; $\mathbf{N R}=$ not reported; $\mathbf{P D G F R}=$ platelet-derived growth factor; $\mathbf{R}$ af $=\mathbf{v}$-raf- 1 murine leukemia viral oncogene homolog 1; VEGFR=vascular endothelial growth factor receptor.

and other agents targeting VEGFRs $-1,-2$, and -3 in $\mathrm{mRCC}$ are illustrated in figure 2. ${ }^{[33,39-45]}$ Additionally, studies carried out in vitro showed that axitinib did not significantly inhibit other receptor kinases that were tested, including colony-stimulating factor (CSF)-1R, fms-like tyrosine kinase (Flt)-3, fibroblast growth factor receptor (FGFR)-1, ret proto-oncogene (RET), epidermal growth factor receptor (EGFR), and met proto-oncogene encoding hepatocyte growth factor (c-Met). ${ }^{[32]}$

\subsection{Axitinib Antitumor Activity}

Axitinib has demonstrated in vivo target modulation and antiangiogenesis in several nonclinical models. ${ }^{[32]}$ In xenograft tumor mouse models across various tumor types, axitinib antitumor activity was associated with marked reduction in tumor vascularization and blood flow, and tumor shrinkage. These were achieved at a range of plasma concentrations consistent with its in vitro potency and were dose dependent. ${ }^{[32]}$ The $\mathrm{C}_{\text {target }}$ value (required in vivo pharmacologic concentration) was determined to be $\sim 0.5 \mathrm{nmol} / \mathrm{L}$ (unbound), which in humans would be equivalent to a $\mathrm{C}_{\text {target }}$ of $\sim 100 \mathrm{nmol} / \mathrm{L}$ (total).

In a phase I study of axitinib in patients with advanced solid tumors, the maximum tolerated dose and recommended dose in humans was de- termined to be $5 \mathrm{mg}$ twice daily on a continuous daily dosing schedule. ${ }^{[46]}$ Hypertension and stomatitis were the main dose-limiting toxicities seen during the phase I study; these were mainly observed with higher doses of axitinib. Other adverse events (AEs) included fatigue, diarrhea, nausea, and vomiting. ${ }^{[46]}$

\section{Pharmacokinetics/Pharmacodynamics}

\subsection{Pharmacokinetics}

Axitinib is administered orally on a proposed standard dosing regimen of $5 \mathrm{mg}$ twice daily with titration as required, and is rapidly absorbed, with peak plasma concentrations measurable within 2-6 hours after dosing in the fed state. ${ }^{[46]}$ Axitinib exhibits linear pharmacokinetics at doses of $2-10 \mathrm{mg}$ twice daily. ${ }^{[46]}$ Peak plasma concentrations are reached in 1-2 hours after dosing in the fasted state, while plasma half-life remains unchanged. ${ }^{[46]}$ Axitinib exists in different crystal forms. With crystal polymorph Form IV, higher plasma levels were observed after overnight fasting, but not with shorter fasting times (e.g. fasting 1 or 2 hours before and after each dose) ${ }^{[47]}$ Findings for polymorph Form XLI are awaited.

Axitinib primarily undergoes hepatic metabolism via the cytochrome P450 (CYP) 3A4 isozyme, 
with some additional metabolism occurring via oxidation by CYP2C19 and CYP1A2 and glucuronidation via uridine diphosphate glucuronosyltransferase (UGT) 1A1. ${ }^{[46]}$ The major circulating axitinib metabolites, the glucuronide and the sulfoxide, are not active. Less than $1 \%$ of the administered drug appears as unchanged drug in the urine. ${ }^{[46]}$

No changes in the pharmacokinetic profile of axitinib or comparator agents were observed when axitinib was administered in combination with chemotherapies including paclitaxel, docetaxel, cisplatin, carboplatin, oxaliplatin, 5-fluorouracil, irinotecan, and/or gemcitabine. ${ }^{[48-52]}$

As both CYP3A4 and 1A2 are known to be inducible, coadministration of axitinib with agents known to be potent inducers is contraindicated. Data from a single patient in a phase I study demonstrated an interaction between axitinib and phenytoin, a potent inducer of several CYP450 isozymes. ${ }^{[46]}$ In this patient, the area under the concentration-time curve from 0 to 24 hours $\left(\mathrm{AUC}_{24}\right)$ and the peak plasma concentration $\left(\mathrm{C}_{\max }\right)$ of axitinib were reduced by 10 -fold, and the patient subsequently experienced disease pro- gression, despite earlier response to axitinib, which ultimately led to their discontinuation from treatment. As a result of this, concomitant use of potent inducers of the CYP3A4 and CYP1A2 isozymes was subsequently excluded during axitinib treatment. In a phase I two-way crossover study of axitinib given with or without rifampicin in Japanese and Caucasian healthy volunteers $(\mathrm{n}=40)$, rifampicin (a potent inducer of drugmetabolizing enzymes including CYP3A4, CYP1A2, and UGT1A1) decreased the AUC from time zero extrapolated to infinity $\left(\mathrm{AUC}_{\infty}\right)$ and $\mathrm{C}_{\max }$ of axitinib (geometric mean reduced to $79 \%$ and $71 \%$, respectively). ${ }^{[53]}$ No differences in pharmacokinetics were observed between Japanese and Caucasian subjects.

Since axitinib is predominantly metabolized by CYP3A4, concomitant use of potent inhibitors with axitinib is also excluded. Data from a phase I two-way crossover study of axitinib alone or coadministered with ketoconazole (a potent CYP3A inhibitor) in healthy volunteers $(\mathrm{n}=32)$ demonstrated that concurrent administration of ketoconazole increased axitinib plasma exposure $\left(\mathrm{AUC}_{\infty}\right)$ and $\mathrm{C}_{\max }$ with approximate

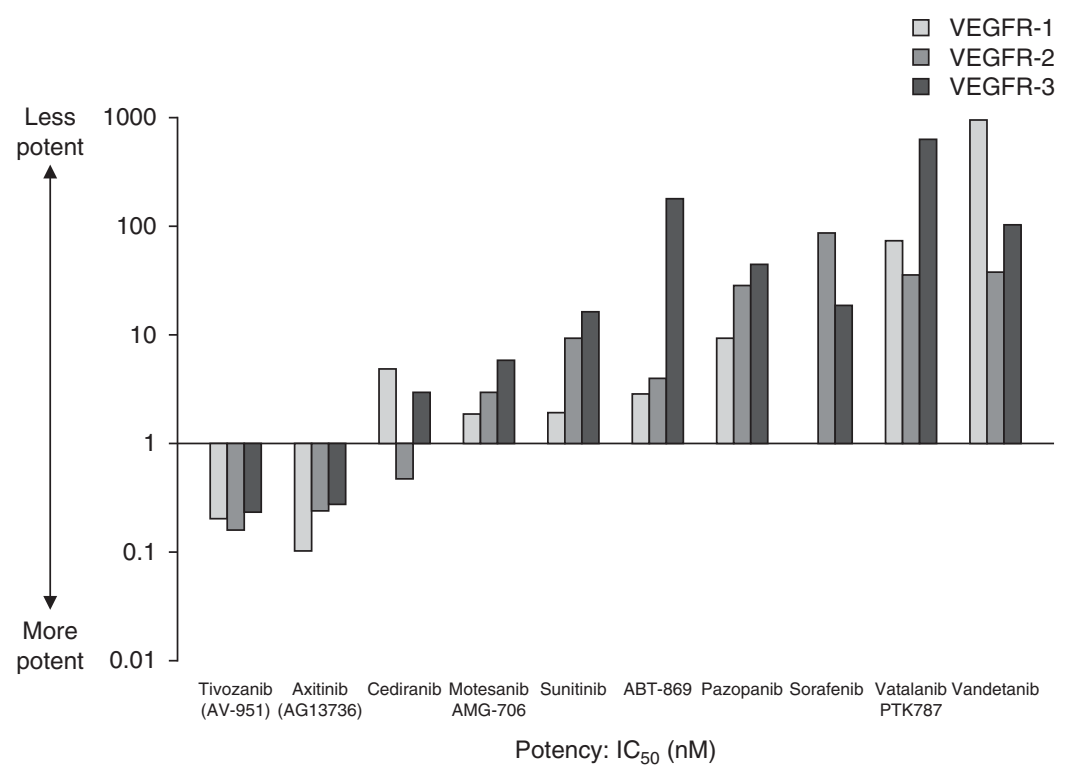

Fig. 2. Relative potency of targeted agents in metastatic renal cell carcinoma (mRCC). ${ }^{[32,33,39-45]} \mathbf{I C}_{50}=$ concentration that produces $50 \%$ inhibition; VEGFR = vascular endothelial growth factor receptor. Reproduced from Bellmunt et al., ${ }^{[33]}$ with permission. 


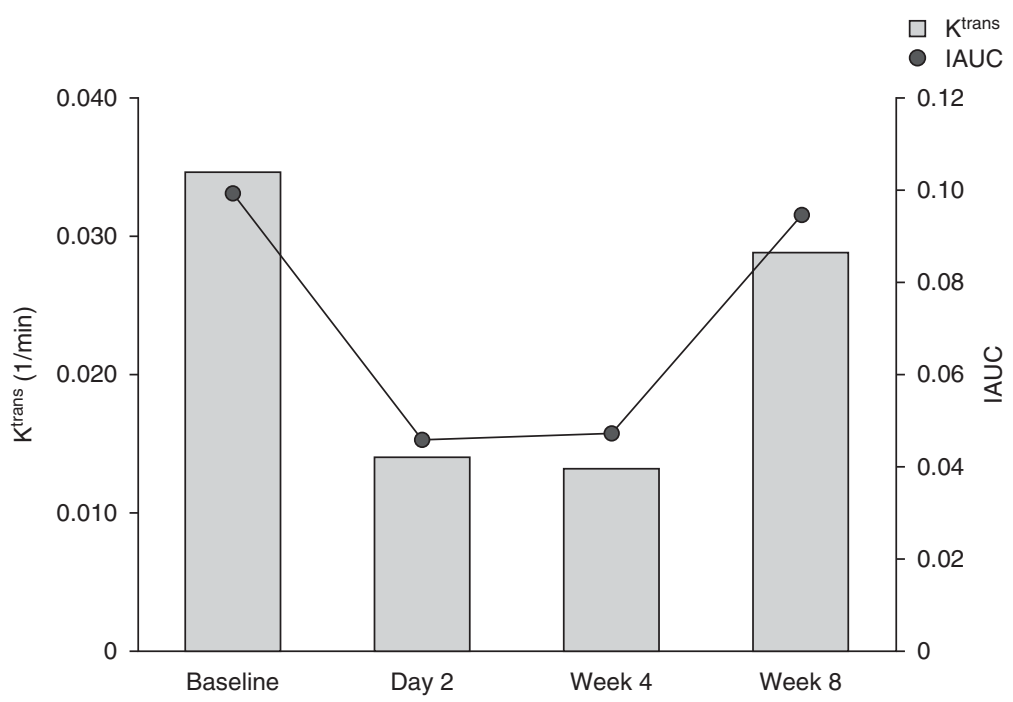

Fig. 3. Quantitative representation of tumor initial area under the curve (IAUC) values mapped over the tumor region $\mathrm{K}^{\text {trans }}$, volume transfer constant. Reproduced from Liu et al., ${ }^{[55]}$ with permission.

2- and 1.5-fold increases in the geometric mean values, respectively. ${ }^{[54]}$ In addition, $\mathrm{C}_{\max }$ occurred 1.5 hours after dosing with axitinib alone compared with 2.0 hours after coadministration with ketoconazole.

Antacids do not have a clinically significant effect on axitinib pharmacokinetics. ${ }^{[46]}$ Coadministration with the proton pump inhibitor, rabeprazole, reduced the rate of axitinib absorption, leading to a decrease in $\mathrm{C}_{\max }$, but had only marginal impact on AUC. ${ }^{[46]}$

\subsection{Pharmacodynamics}

In a study measuring the exposure-response relationship of axitinib in patients with advanced solid tumors, $a>50 \%$ decrease in the volume transfer coefficient $\left(\mathrm{K}^{\text {trans }}\right)$ and initial area under the curve was demonstrated by day 2 of therapy, and persisted through week 4 of treatment (figure 3). ${ }^{[55]} \mathrm{A}$ linear correlation suggested that increased axitinib exposure is associated with higher efficacy, as indicated by decreased tumor perfusion and volume.

\section{Phase II Clinical Study Results}

Axitinib has been studied in three phase II, single-arm, multicenter, clinical trials investigat- ing its efficacy, safety and pharmacodynamics in patients with $\mathrm{mRCC}$ (table II). ${ }^{[56,57]}$

\section{1 Efficacy}

In the first study, conducted in 52 patients with cytokine-refractory $\mathrm{mRCC}$, patients received axitinib (administered as $5 \mathrm{mg}$ twice daily) in the fasted state in 28-day treatment cycles until disease progression or unacceptable toxicity. ${ }^{[56,58]}$ Results from this study demonstrated an ORR of

Table II. Summary of efficacy findings in key phase II studies [n (\%)]

\begin{tabular}{lcl}
\hline Best response & $\begin{array}{l}\text { Cytokine refractory } \\
(\mathrm{n}=52)^{[56]}\end{array}$ & $\begin{array}{l}\text { Sorafenib refractory } \\
(\mathrm{n}=62)^{[57]}\end{array}$ \\
\hline $\begin{array}{l}\text { Objective response rate } \\
\text { complete response }\end{array}$ & $23(44)$ & $14(23)$ \\
$\quad$ partial response & $21(40)$ & $14(23)$ \\
$\begin{array}{l}\text { Stable disease } \\
\geq 8 \text { wk }\end{array}$ & $11(18)$ \\
$\geq 24$ wk & $22(42)$ & \\
Disease progression & $4(25)$ & \\
Missing data & $3(6)$ & $25(40)$ \\
PFS (mo) & 13.7 & $12(19)$ \\
OS (mo) & 29.9 & 7.4 \\
\hline OS $=$ overall survival; & NR $=$ not reported; & PFS $=$ progression-free \\
survival. & & \\
\hline
\end{tabular}


44.2\% (23 patients; $95 \%$ CI 30.5, 58.7), as indicated by two complete responses (4\%) and 21 partial responses (PR; 40\%) based on the Response Evaluation Criteria In Solid Tumors (RECIST). ${ }^{[59]}$ Additionally, 22 patients (42\%) showed stable disease (SD) lasting for longer than 8 weeks, including $13(25 \%)$ patients with SD for at least 24 weeks. The median duration of response was 23.0 months. The median time to progression was 15.7 months (95\% CI 8.4, 23.4), and the median OS was 29.9 months (95\% CI 20.3, not estimable).
Maximum percentage decrease in target lesion size, based on RECIST is shown in figure 4a.

The second phase II study evaluated axitinib in 62 patients with advanced and refractory RCC who had not responded to sorafenib-based therapy. ${ }^{[57]}$ In this study, prior therapies were not limited to sorafenib, but could also include cytotoxic therapies, cytokines and other targeted therapies such as sunitinib, bevacizumab, and temsirolimus. PR was observed in 14 patients giving an ORR of $22.6 \%$, (95\% CI 12.9, 35.0), SD

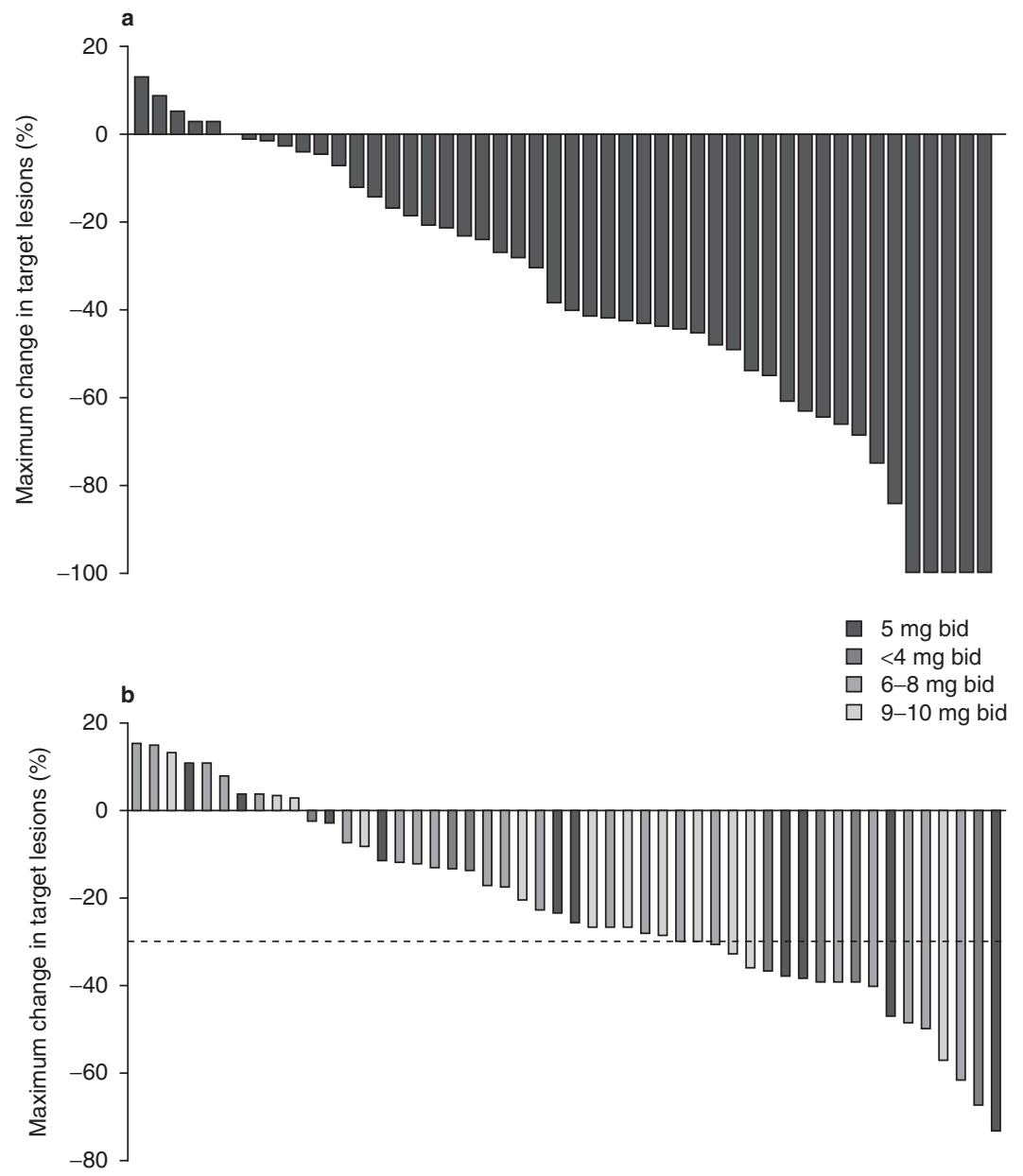

Fig. 4. Tumor responses from phase II trials of axitinib in patients with metastatic renal cell carcinoma (mRCC). Each bar represents one patient. Maximum percentage reduction in tumor size of target lesions by Response Evaluation Criteria In Solid Tumors (RECIST) $[-100 \%=$ complete response; $-30 \%=$ partial response; $n=48]$. Reproduced from (a) Rini et al. ${ }^{[57]}$ and (b) Rixe et al., ${ }^{[56]}$ with permission bid = twice daily; $\mathbf{C R}=$ complete response; $\mathbf{P R}=$ partial response. 
Table III. Common adverse events reported in phase II clinical trials ${ }^{[56,57]}$

\begin{tabular}{|c|c|c|c|c|}
\hline \multirow[t]{2}{*}{ Adverse event } & \multicolumn{2}{|c|}{ Cytokine refractory $(n=52)^{[56]}$} & \multicolumn{2}{|c|}{ Sorafenib refractory $(n=62)^{[57]}$} \\
\hline & all grades [n (\%)] & grade $3 / 4[n(\%)]$ & all grades [n (\%)] & grade $3 / 4[n(\%)]$ \\
\hline Diarrhea & $31(60)$ & $5(10)$ & $38(61)$ & $9(15)$ \\
\hline Hypertension & $30(58)$ & $8(15)$ & $28(45)$ & $10(16)$ \\
\hline Fatigue & $27(52)$ & $4(8)$ & $48(77)$ & $10(16)$ \\
\hline Nausea & $23(44)$ & 0 & $27(44)$ & $4(7)$ \\
\hline Hoarseness & $19(37)$ & 0 & NR & NR \\
\hline Dyspnea & NR & NR & $24(39)$ & $9(15)$ \\
\hline Dysphonia & NR & NR & $23(37)$ & 0 \\
\hline Hand-foot syndrome & NR & NR & $22(36)$ & $10(16)$ \\
\hline Anorexia & $18(35)$ & $1(2)$ & $30(48)$ & 0 \\
\hline Mucosal inflammation & NR & NR & $21(34)$ & $1(2)$ \\
\hline Dry skin & $17(33)$ & 0 & NR & NR \\
\hline Weight loss & $14(27)$ & 0 & $19(31)$ & $3(5)$ \\
\hline Dyspepsia & $12(23)$ & 0 & NR & NR \\
\hline Vomiting & $11(21)$ & 0 & $20(32)$ & $3(5)$ \\
\hline Cough & $\mathrm{NR}$ & NR & $18(29)$ & 0 \\
\hline Headache & $\mathrm{NR}$ & NR & $18(29)$ & $1(2)$ \\
\hline Arthralgia & NR & NR & $17(27)$ & $2(3)$ \\
\hline Constipation & NR & NR & $16(26)$ & 0 \\
\hline Dysgeusia & NR & NR & $14(23)$ & 0 \\
\hline Abdominal pain & NR & NR & $13(21)$ & $7(11)$ \\
\hline Pain in extremity & $\mathrm{NR}$ & NR & $13(21)$ & $2(3)$ \\
\hline
\end{tabular}

$\mathbf{N R}=$ not reported.

in 11 patients (18\%), and progressive disease in 25 patients (40\%). Some degree of tumor shrinkage was seen in 40 of 50 patients $(80.0 \%)$ for whom post-baseline data were available.

In this study, tumor responses were observed within the group of patients who dose-titrated to $>5 \mathrm{mg}$ twice daily $(7 / 33 ; 21 \%)$, as well as in patients who remained on $5 \mathrm{mg}$ twice daily or who were dose-modified to $<5 \mathrm{mg}$ twice daily $(7 / 29 ; 24 \%)$. Maximum percentage reduction in target lesions (by RECIST) during treatment with axitinib based on dose titration is illustrated in figure $4 \mathrm{~b}$. These results suggest that axitinib dose titration (i.e. axitinib given at a higher dose [above its standard starting dose]), may improve the response to treatment in some patients. This is being investigated in an ongoing randomized, double-blind, phase II study of axitinib with or without dose titration in patients with $\mathrm{mRCC} .^{[60]}$

After a median follow-up of 22.7 months $(95 \%$ CI 6.7, 11.0), the median PFS was 7.4 months
(95\% CI 6.7, 11.0), and median OS was 13.6 months (95\% CI 8.4, 18.8).

In the third phase II study in Japanese patients with $\mathrm{mRCC}$ refractory to previous cytokine-based treatment, patients $(n=64)$ received continuous dosing of axitinib (starting dose: $5 \mathrm{mg}$ twice daily). ${ }^{[58]}$ An ORR of $55 \%$ was reported in this study and median PFS was 12.9 months $(95 \%$ CI 9.8, 15.6).

\subsection{Safety and Tolerability}

For single-agent axitinib, the most common AEs reported are hypertension, fatigue, and gastrointestinal toxicity (table III). ${ }^{[56,57]}$ These AEs are an expected class effect due to the known mechanism of action of the drug. The majority of AEs are manageable with dose modification and supportive care; hypertension is generally easily managed with standard antihypertensive drugs. ${ }^{[56,57]}$

In the three phase II studies in renal carcinoma, no unexpected AEs occurred. In the Western 
trial of cytokine-refractory patients, the most common all-causality treatment-related AEs included diarrhea (60\%), hypertension (58\%), and fatigue $(52 \%){ }^{[56]}$ The most common grade $3-4$ AEs were hypertension (15\%), diarrhea (10\%), and fatigue ( $8 \%$ ), and no grade 3-4 hematologic toxicities were noted. Only four patients reported treatment-related proteinuria, all of which were grade $1-2$. Of the 52 patients enrolled, ten patients discontinued due to treatment-related AEs. ${ }^{[56]}$

In sorafenib-refractory patients, the most common all-causality AEs were fatigue (77\%), diarrhea (61\%), anorexia (48\%), and hypertension (45\%). ${ }^{[57]}$ All-causality grade 3-4 AEs included hand-foot syndrome (HFS; 16.1\%), fatigue (16.1\%), hypertension (16.1\%), dyspnea (14.5\%), diarrhea (14.5\%), dehydration (8.1\%), and hypotension (6.5\%). Of 62 patients enrolled, treatment was discontinued in 22 patients due to AEs (of these, 12 were attributed to study treatment). ${ }^{[57]}$

Common treatment-related AEs reported in the Japanese trial of cytokine-refractory patients were HFS (73\%), hypertension (66\%), diarrhea (66\%), and hoarseness (53\%). In all, 18 patients developed proteinuria $\geq 2 \mathrm{~g} / 24$ hours during treatment and required dose reduction or treatment interruption/discontinuation. ${ }^{[58]}$ Of note, the incidences of HFS and proteinuria in the Japanese study were higher than those reported in the Western study in cytokine-refractory mRCC patients.

These phase II data indicate that the continuous administration and the constant dose of axitinib appear to have acceptable tolerability and are compatible with long-term administration. Certainly, in the Western study in cytokine-refractory mRCC, patients have received axitinib for more than 3 years with no cumulative toxicity. ${ }^{[56]}$

\subsection{Diastolic Blood Pressure and Clinical Efficacy}

An interesting association between diastolic blood pressure (DBP) and clinical efficacy appears to exist with axitinib therapy. Hypertension is a commonly observed event during treatment with axitinib and other VEGF signal inhibitors, and is generally manageable with standard anti- hypertensive agents. In a retrospective analysis of axitinib treatment across multiple tumor types, the occurrence of DBP $\geq 90 \mathrm{mmHg}$ was associated with increased OS. ${ }^{61]}$

A pooled analysis of the two axitinib phase II mRCC studies $(n=114)$ explored the relationship between pharmacokinetics, DBP, and clinical efficacy. ${ }^{[61]}$ Response was evaluated based on RECIST-defined ORR, OS, and changes in tumor size (the sum of lesion diameter; SLD). DBP and mean steady-state AUC during axitinib treatment were used as predictors of clinical efficacy in mRCC patients using logistic regression.

Using this methodology, DBP $\geq 90 \mathrm{mmHg}$ and AUC appear to be independent predictors of clinical efficacy, with an improved clinical response (as indicated by a reduction in SLD) associated with increasing axitinib plasma exposure (AUC).

There was an increased probability $(\mathrm{p}<0.05)$ of achieving a PR with increasing AUC, with a $47 \%$ and $22 \%$ increase in the probability of achieving a PR for every $100 \mathrm{ng} / \mathrm{h} / \mathrm{mL}$ increase in AUC for cytokine-refractory and sorafenib-refractory patients, respectively. Additionally, improved clinical response was associated with greater changes in DBP. Logistic regression analysis showed that the probability of experiencing a PR increased with greater maximum DBP $(\mathrm{p}<0.05)$, and patients had an $86 \%$ increase in the probability of achieving a PR for every $10 \mathrm{mmHg}$ increase in DBP $\left(\mathrm{p}<0.05\right.$; figure 5). ${ }^{[62]}$

OS was also longer in patients with at least one DBP measurement $\geq 90 \mathrm{mmHg}$ during axitinib therapy $(\mathrm{p}<0.05)$, with a median OS of 130 weeks for patients with $\mathrm{DBP} \geq 90 \mathrm{mmHg}$ compared with just 42 weeks for patients without $\mathrm{DBP} \geq 90 \mathrm{mmHg}$. Interestingly, increases in AUC were not highly correlated with changes in DBP.

Logistic regression and Kaplan-Meier analyses showed that increased axitinib exposure and DBP $\geq 90 \mathrm{mmHg}$ were independently associated with several measures of clinical improvement, including longer OS, greater probability of a PR, and greater reductions in SLD.

In the Japanese phase II study, ${ }^{[58]}$ patients with at least one recorded DBP reading $\geq 90 \mathrm{mmHg}$ during the first 28 days of treatment had significantly longer PFS compared with those without 
a DBP reading $\geq 90 \mathrm{mmHg}$ (median PFS, 14.6 vs 9.8 months; $\mathrm{p}=0.02$ ).

These data suggest that in patients with $\mathrm{mRCC}$, the occurrence of $\mathrm{DBP} \geq 90 \mathrm{mmHg}$ during axitinib treatment is not merely a reflection of higher axitinib drug levels and, therefore, may be of clinical interest and worthy of investigation as a potential prognostic biomarker.

\section{Ongoing Clinical Studies}

Clinical investigation of axitinib is ongoing in one phase II study ${ }^{[60,63]}$ and two large-scale phase III trials in patients with $\mathrm{mRCC}{ }^{[64,65]}$

\section{1 Ongoing Phase II Clinical Study: \\ The AGILE 1046 Trial}

The AGILE 1046 trial is a prospective, randomized trial to evaluate (i) the efficacy of axitinib treatment with or without dose titration in treatment-naïve mRCC patients; (ii) axitinib-related changes in blood pressure (BP) using 24-hour ambulatory BP monitoring and telemedicine in a subset of patients; and (iii) axitinib pharmacokinetics over 6 hours, time-matched with BP measurements prior to each pharmacokinetic sample. ${ }^{[63]}$
Patients will be randomized 1:1 to receive axitinib $5 \mathrm{mg}$ twice daily plus dose titration with axitinib (Arm A) or placebo (Arm B). Only the dose titration portion will be blinded. Patients not meeting randomization (dose-titration) criteria will continue receiving axitinib without dose titration in a separate, non-randomized $\operatorname{arm}(\operatorname{Arm} \mathrm{C}) .{ }^{[60,63]}$

The primary endpoint is ORR, and secondary endpoints include PFS, OS, duration of response, safety, pharmacokinetics, BP, and translational medicine assessments. ${ }^{[60,63]}$ Estimated enrollment is 200 and the trial is currently recruiting participants with an estimated enrollment period of 2 years. ${ }^{[63]}$

\subsection{Ongoing Phase III Clinical Studies}

\subsubsection{The AGILE 1032 Trial}

The AGILE 1032 trial is a global, phase III, randomized, open-label study that will compare the efficacy and safety of second-line axitinib $5 \mathrm{mg}$ twice daily or sorafenib $400 \mathrm{mg}$ twice daily (both with continuous dosing) therapy in 723 patients with mRCC refractory to one prior firstline therapy. ${ }^{[64]}$ The primary endpoint is PFS, with secondary endpoints including OS, response rate, duration of response, safety and tolerability,

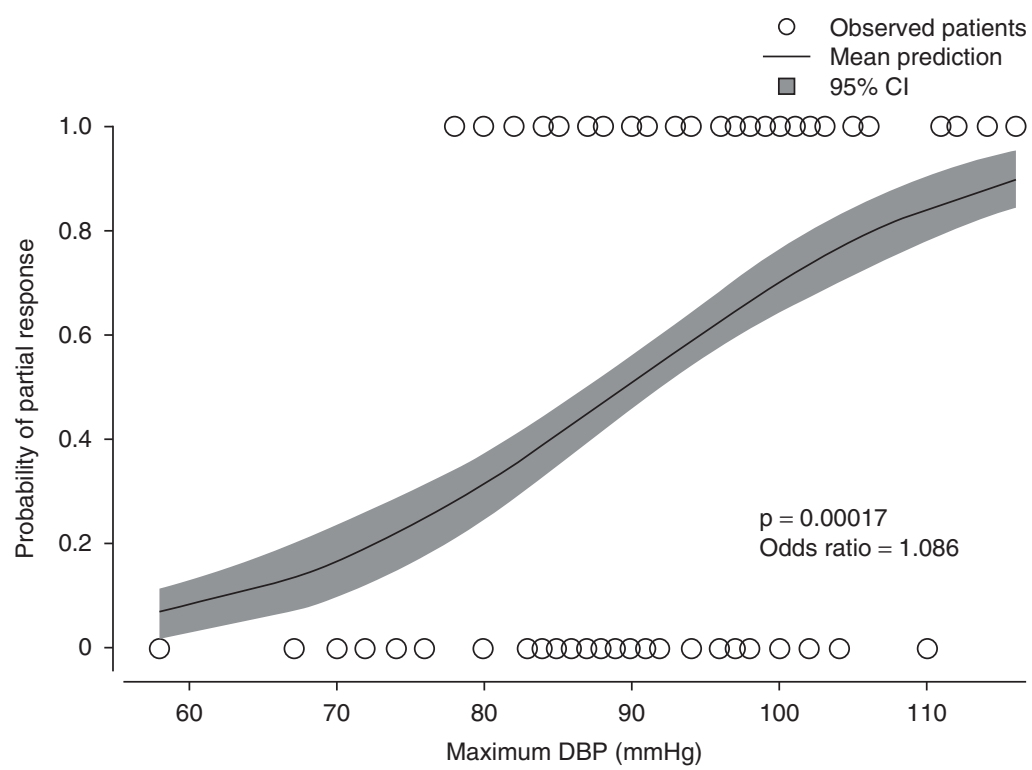

Fig. 5. Probability of a partial response with maximum diastolic blood pressure (DBP). Reproduced from Rixe et al., ${ }^{[62]}$ with permission. 


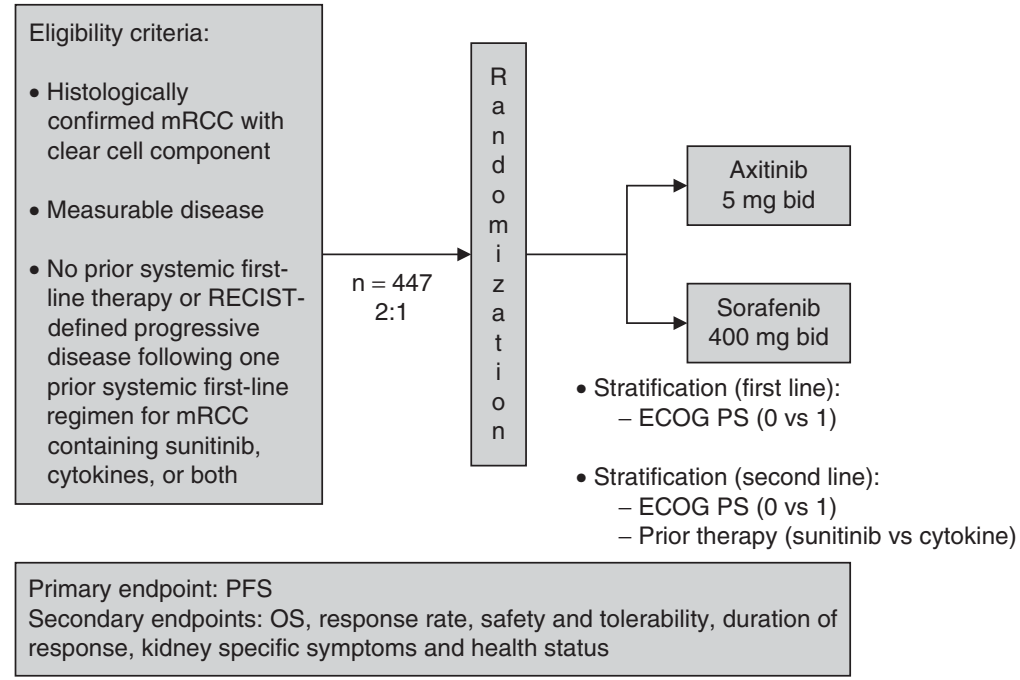

Fig. 6. Study schema for AGILE 1051. ${ }^{[65]}$ bid=twice daily; ECOG PS=Eastern Cooperative Oncology Group Performance Status; $\mathbf{m R C C}=$ metastatic renal cell carcinoma; $\mathbf{O S}=$ overall survival; $\mathbf{P F S}=$ progression-free survival; $\mathbf{R E C I S T}=$ Response Evaluation Criteria In Solid Tumors.

and specific renal symptoms and health status measures. This 3-year trial has completed accrual as of April 2010 and is expected to report out in 2011.

\subsubsection{The AGILE 1051 Trial}

The second trial is a randomized, open-label, phase III study (AGILE 1051 trial) evaluating first- and second-line axitinib $5 \mathrm{mg}$ twice daily versus sorafenib $400 \mathrm{mg}$ twice daily (again, both with continuous dosing) in Asian and non-Asian patients with $\mathrm{mRCC}$ who have either received no prior systemic first-line therapy or have progressed after one prior systemic first-line regimen for metastatic disease containing sunitinib, cytokines, or both. ${ }^{[65]}$ The primary and secondary endpoints are the same as for the AGILE 1032 trial. At the time of writing, trial 1051 is still recruiting, and has an estimated enrollment of 447 patients. A schema for this trial is shown in figure 6 .

\section{Conclusions and Outlook}

Axitinib is a potent and selective inhibitor of VEGFR-1, -2, and -3, delivered orally, with a convenient schedule of administration. Axitinib has been shown to reduce vascular permeability, tumor vascularization and tumor volume, and has demonstrated antitumor activity as a single agent in patients with cytokine- and/or sorafenibrefractory $\mathrm{mRCC}$. The activity range of axitinib is the highest when compared with other active drugs currently approved for use in $\mathrm{mRCC}$, and raises high expectations. Axitinib also has a favorable and non-cumulative tolerability profile associated with manageable AEs, which are generally mild to moderate in severity. Potential associations between the efficacy of axitinib and DBP are currently under evaluation, with promising preliminary results. The place of axitinib in the oncologist's armamentarium and the future role of the drug in the treatment algorithm for $\mathrm{mRCC}$ will be further elucidated in the two ongoing, large-scale, phase III studies in this disease.

\section{Acknowledgments}

Martin Gore acknowledges NHS funding to the NIHR Biomedical Research Centre at the Royal Marsden Hospital, London, UK, and has received honoraria from Pfizer, Roche, Wyeth, Bayer, Novartis, GSK and Aveo. Editorial support was provided by Baxter Jeffs at ACUMED ${ }^{\circledR}$ (Tytherington, UK), and was funded by Pfizer, Inc. 


\section{References}

1. Parkin DM, Bray F, Ferlay J, et al. Global cancer statistics, 2002. CA Cancer J Clin 2005; 55: 74-108

2. Ferlay J, Shin HR, Bray F, et al. GLOBOCAN 2008, cancer incidence and mortality worldwide: IARC cancer base no. 10. Lyon: International Agency for Research on Cancer, 2010 [online]. Available from URL: http://globocan.iarc.fr [Accessed 2011 May 10]

3. National Comprehensive Cancer Network. NCCN clinical practice guidelines in oncology: Kidney Cancer v.2.2010 [online]. Available from URL: http://www.ncen.org/pro fessionals/physician_gls/f_guidelines.asp [Accessed 2010 Dec 11]

4. Pantuck AJ, Zisman A, Belldegrun AS. The changing natural history of renal cell carcinoma. J Urol 2001; 166: 1611-23

5. Brieger $\mathbf{J}$, Weidt EJ, Lindblad $P$, et al. Inverse regulation of vascular endothelial growth factor and VHL tumor suppressor gene in sporadic renal cell carcinomas is correlated with vascular growth: an in vivo study on 29 tumors. J Mol Med 1999; 77: 505-10

6. Gabrilovich DI, Ishida T, Nadaf S, et al. Antibodies to vascular endothelial growth factor enhance the efficacy of cancer immunotherapy by improving endogenous dendritic cell function. Clin Cancer Res 1999; 5: 2963-70

7. Rini BI, Small EJ. Biology and clinical development of vascular endothelial growth factor-targeted therapy in renal cell carcinoma. J Clin Oncol 2005; 23: 1028-43

8. Schoenfeld AR, Parris T, Eisenberger A, et al. The von Hippel-Lindau tumor suppressor gene protects cells from UV-mediated apoptosis. Oncogene 2000; 19: 5851-7

9. Motzer RJ, Bander NH, Nanus DM. Renal-cell carcinoma. N Engl J Med 1996; 335: 865-75

10. Lam JS, Leppert JT, Belldegrun AS, et al. Novel approaches in the therapy of metastatic renal cell carcinoma. World J Urol 2005; 23: 202-12

11. Fisher RI, Rosenberg SA, Fyfe G. Long-term survival update for high-dose recombinant interleukin-2 in patients with renal cell carcinoma. Cancer J Sci Am 2000; 6: Suppl. 1: S55-7

12. Négrier S, Escudier B, Lasset C, et al. Recombinant human interleukin-2, recombinant human interferon alfa-2a, or both in metastatic renal-cell carcinoma. N Engl $\mathbf{J}$ Med 1998; 338: $1272-8$

13. McDermott DF, Regan MM, Clark JI, et al. Randomized phase III trial of high dose interleukin-2 versus subcutaneous interleukin-2 and interferon in patients with metastatic renal cell carcinoma [published erratum appears in J Clin Oncol 2005; 23: 2877]. J Clin Oncol 2005; 23: $133-41$

14. Motzer RJ, Murphy BA, Bacik J, et al. Phase III trial of interferon alfa-2a with or without 13-cis-retinoic acid for patients with advanced renal cell carcinoma. J Clin Oncol 2000; 18: 2972-80

15. Yang JC, Sherry RM, Steinberg SM, et al. Randomized study of high-dose and low-dose interleukin-2 in patients with metastatic renal cancer. J Clin Oncol 2003; 21: 3127-32

16. Coppin C, Porzsolt F, Awa A, et al. Immunotherapy for advanced renal cell cancer. Cochrane Database Syst Rev 2005; (3): CD001425
17. Motzer RJ, Bacik J, Murphy BA, et al. Interferon-alfa as a comparative treatment for clinical trials of new therapies against advanced renal cell carcinoma. J Clin Oncol 2002; 20: $289-96$

18. Gore ME, Griffin CL, Hancock B, et al. Interferon alfa-2a versus combination therapy with interferon alfa- $2 \mathrm{a}$, interleukin-2, and fluorouracil in patients with untreated metastatic renal cell carcinoma (MRC RE04/EORTC GU 30012): an open-label randomised trial. Lancet 2010; 375: 641-8

19. Parton M, Gore M, Eisen T. Role of cytokine therapy in 2006 and beyond for metastatic renal cell cancer. J Clin Oncol 2006; 24: 5584-92

20. Escudier B, Pluzanska A, Koralewski P, et al. Bevacizumab plus interferon alfa-2a for treatment of metastatic renal cell carcinoma: a randomised, double-blind phase III trial. Lancet 2007; 370: 2103-11

21. Escudier B, Eisen T, Stadler WM, et al. Sorafenib in advanced clear-cell renal-cell carcinoma. N Engl J Med 2007; 356: $125-34$

22. Hudes G, Carducci M, Tomczak P, et al. Temsirolimus, interferon alfa, or both for advanced renal-cell carcinoma. N Engl J Med 2007; 356: 2271-81

23. Motzer RJ, Hutson TE, Tomczak P, et al. Sunitinib versus interferon alfa in metastatic renal-cell carcinoma. N Engl J Med 2007; 356: 115-24

24. Motzer RJ, Escudier B, Oudard S, et al. Efficacy of everolimus in advanced renal cell carcinoma: a double-blind, randomised, placebo-controlled phase III trial. Lancet 2008; 372: 449-56

25. Sternberg CN, Davis ID, Mardiak J, et al. Pazopanib in locally advanced or metastatic renal cell carcinoma: results of a randomized phase III trial. J Clin Oncol 2010; 28: 1061-8

26. Motzer RJ, Hutson TE, Tomczak P, et al. Overall survival and updated results for sunitinib compared with interferon alfa in patients with metastatic renal cell carcinoma. $\mathrm{J}$ Clin Oncol 2009; 27: 3584-90

27. Ellis LM, Hicklin DJ. VEGF-targeted therapy: mechanisms of anti-tumor activity. Nat Rev Cancer 2008; 8: 579-91

28. Ferrara N, Gerber HP, LeCouter J. The biology of VEGF and its receptors. Nat Med 2003; 9: 669-76

29. Bertolini F, Shaked Y, Mancuso P, et al. The multifaceted circulating endothelial cell in cancer: towards marker and target identification. Nat Rev Cancer 2006; 6: 835-45

30. Hicklin DJ, Ellis LM. Role of the vascular endothelial growth factor pathway in tumor growth and angiogenesis. J Clin Oncol 2005; 23: 1011-27

31. Tammela T, Zarkada G, Wallgard E, et al. Blocking VEGFR-3 suppresses angiogenic sprouting and vascular network formation. Nature 2008; 454: 656-60

32. Hu-Lowe DD, Zou HY, Grazzini ML, et al. Nonclinical antiangiogenesis and antitumor activities of axitinib (AG013736), an oral, potent, and selective inhibitor of vascular endothelial growth factor receptor tyrosine kinases 1, 2, 3 . Clin Cancer Res 2008; 14: 7272-83

33. Bellmunt J. Second-line treatment: which treatment and when? Pfizer Symposium. Presented at the 5th European International Kidney Cancer Symposium (EIKCS); 2010 May 7-8; London 
34. Pfizer Ltd. SUTENT ${ }^{\circledR}$ (sunitinib malate). EU Summary of product characteristics, $2010 \mathrm{Jul}$

35. Schmidinger M, Bellmunt J. Plethora of agents, plethora of targets, plethora of side effects in metastatic renal cell carcinoma. Cancer Treat Rev 2010; 36 (5): 416-24

36. Bayer Plc. Nexavar ${ }^{\circledR}$ (sorafenib tosylate) EU Summary of product characteristics, 2009 Nov

37. Wilhelm SM, Carter C, Tang L, et al. BAY 43-9006 exhibits broad spectrum oral antitumor activity and targets the $\mathrm{RAF} / \mathrm{MEK} / \mathrm{ERK}$ pathway and receptor tyrosine kinases involved in tumor progression and angiogenesis. Cancer Res 2004; 64 (19): 7099-109

38. Kumar R, Knick VB, Rudolph SK, et al. Pharmacokineticpharmacodynamic correlation from mouse to human with pazopanib, a multikinase angiogenesis inhibitor with potent antitumor and antiangiogenic activity. Mol Cancer Ther 2007; 6 (7): 2012-21

39. Albert DH, Tapang P, Magoc TJ, et al. Preclinical activity of ABT-869, a multitargeted receptor tyrosine kinase inhibitor. Mol Cancer Ther 2006; 5 (4): 995-1006

40. Chow LQ, Eckhardt SG. Sunitinib: from rational design to clinical efficacy. J Clin Oncol 2007; 25(7): 884-96

41. Eskens FALM, de Jonge M, Esteves B, et al. Updated results from a phase I study of AV-951 (KRN951), a potent and selective VEGFR-1, -2 and -3 tyrosine kinase inhibitor, in patients with advanced solid tumors [abstract no. LB-201]. 99th American Association for Cancer Research (AACR) Annual Meeting; 2008 Apr 12-16; San Diego (CA)

42. Morabito A, De Maio E, Di Maio M, et al. Tyrosine kinase inhibitors of vascular endothelial growth factor receptors in clinical trials: current status and future directions. Oncologist 2006; 11 (7): 753-64

43. Morabito A, Piccirillo MC, Falasconi F, et al. Vandetanib (ZD6474), a dual inhibitor of vascular endothelial growth factor receptor (VEGFR) and epidermal growth factor receptor (EGFR) tyrosine kinases: current status and future directions. Oncologist 2009; 14 (4): 378-90

44. Polverino A, Coxon A, Starnes C, et al. AMG 706, an oral, multikinase inhibitor that selectively targets vascular endothelial growth factor, platelet-derived growth factor, and kit receptors, potently inhibits angiogenesis and induces regression in tumor xenografts. Cancer Res 2006; 66 (17): $8715-21$

45. Sonpavde G, Hutson TE, Sternberg CN. Pazopanib for the treatment of renal cell carcinoma and other malignancies. Drugs Today (Barc) 2009; 45 (9): 651-61

46. Rugo HS, Herbst RS, Liu G, et al. Phase I trial of the oral antiangiogenesis agent AG-013736 in patients with advanced solid tumors: pharmacokinetic and clinical results. Clin Oncol 2005; 23: 5474-83

47. Pithavala YK, Mount J, Toh M, et al. Effect of food on the pharmacokinetics of axitinib (AG-013736) in healthy volunteers [abstract no. 233]. 99th AACR Annual Meeting; 2008 Apr 12-16; San Diego (CA)

48. Kozloff MF, Martin LP, Krzakowski M, et al. A phase I study of axitinib (AG-013736) combined with paclitaxel/carboplatin $(\mathrm{P} / \mathrm{C})$, gemcitabine/cisplatin $(\mathrm{Gem} / \mathrm{Cis})$ or pemetrexed/cisplatin (Pem/Cis) in patients (pts) with solid tumours, including advanced non-small cell lung cancer NSCLC) [abstract no. 1231]. Eur J Cancer Suppl 2009; 7 (2): 129
49. Tortorici MA, Chen Y, Kim S, et al. Pharmacokinetic (PK) analysis of co-administration of axitinib (AG-013736; AG) and common chemotherapy (CT) regimens (paclitaxel/ carboplatin [Pac/Carb]; paclitaxel [Pac]; docetaxel [Doc]; capecitabine [Cap]; gemcitabine/cisplatin $[\mathrm{Gem} / \mathrm{Cis}]$; pemetrexed/cisplatin [Pem/Cis]) [abstract no. PIII-25]. 111th Meeting of the American Society of Clinical Pharmacology and Therapeutics (ASCPT); 2010 Mar 17-20; Atlanta (GA)

50. Sharma S, Abhyankar V, Burgess RE, et al. A phase 1 study of axitinib (AG-013736) in combination with chemotherapy and in combination with bevacizumab plus chemotherapy in patients with metastatic colorectal cancer and other solid tumors. Ann Oncol 2010; 21 (2): 297-304

51. Spano J-P, Chodkiewicz C, Maurel J, et al. A randomized phase 2 study of axitinib (AG-013736) and gemcitabine versus gemcitabine alone in advanced pancreatic cancer, preceded by a phase 1 component [abstract no. O-0011]. 9th World Congress on Gastrointestinal Cancer (WCGI); 2008 Jun 27-30; Barcelona

52. Martin LP, Kozloff M, Herbst RS, et al. Phase I study of axitinib (AG-013736) in combination with chemotherapy in patients (pts) with advanced solid tumours [abstract no. 472P]. 33rd ESMO Congress; 2008 Sep 12-16; Stockholm

53. Pithavala YK, Tortorici M, Toh M, et al. Effect of rifampin on the pharmacokinetics of axitinib (AG-013736) in Japanese and Caucasian healthy volunteers. Cancer Chemother Pharmacol 2010; 65: 563-70

54. Pithavala YK, Tong W, Mount J, et al. Effect of ketoconazole on the pharmacokinetics of axitinib in healthy volunteers. Invest New Drugs. Epub 2010 Aug 26

55. Liu G, Rugo HS, Wilding G, et al. Dynamic contrast-enhanced magnetic resonance imaging as a pharmacodynamic measure of response after acute dosing of AG-013736, an oral angiogenesis inhibitor, in patients with advanced solid tumors: results from a phase I study. J Clin Oncol 2005; 23: 5464-73

56. Rixe O, Bukowski RM, Michaelson MD, et al. Axitinib treatment in patients with cytokine-refractory metastatic renal-cell cancer: a phase II study. Lancet Oncol 2007; 8: 975-84

57. Rini BI, Wilding G, Hudes G, et al. Phase II study of axitinib in sorafenib-refractory metastatic renal cell carcinoma. J Clin Oncol 2009; 27: 4462-8

58. Tomita $\mathrm{Y}$, Uemura $\mathrm{H}$, Fujimoto $\mathrm{H}$, et al. Key predictive factors of axitinib (AG-013736)-induced proteinuria and efficacy: a Japanese phase II study in patients with cytokinerefractory metastatic renal cell cancer (mRCC) [abstract no. 902P]. 35th Annual Congress of the European Society for Medical Oncology (ESMO); 2010 Oct 8-12; Milan

59. Therasse P, Arbuck SG, Eisenhauer EA. New guidelines to evaluate the response to treatment in solid tumors. J Natl Cancer Inst 2000; 92: 205-16

60. Pfizer Inc. Randomized, double-blind phase 2 study of axitinib (AG-013736) with or without dose titration in patients with metastatic renal cell carcinoma [ClinicalTrials.gov identifier NCT00835978]. US National Institutes of Health, ClinicalTrials.gov [online]. Available from URL: http:// www.clinicaltrials.gov [Accessed 2011 May 10]

61. Rini BI, Schiller JH, Fruehauf JP, et al. Association of diastolic blood pressure $(\mathrm{dBP})>90 \mathrm{mmHg}$ with overall survival (OS) in patients treated with axitinib (AG- 013736) [abstract no. 3543]. 44th ASCO Annual Meeting; 2008 May 30-Jun 3; Chicago (IL) 
62. Rixe O, Dutcher J, Motzer R, et al. Diastolic blood pressure $(\mathrm{dBP})$ and pharmacokinetics (PK) as predictors of axitinib efficacy in metastatic renal cell cancer (mRCC) [abstract no. 5045]. 45th ASCO Annual Meeting; 2009 May 29-Jun 2; Orlando (FL)

63. Jonasch E, Bair AH, Chen Y, et al. Axitinib with or without dose titration as front-line therapy for metastatic renal cell carcinoma (mRCC) [abstract no. TPS235]. 46th Annual Meeting of the American Society of Clinical Oncology; 2010 Jun 4-8; Chicago (IL)

64. Pfizer Inc. Axitinib (AG 013736) as second line therapy for metastatic renal cell cancer: AGILE 1032 trial [Clinical Trials.gov identifier NCT00678392]. US National In- stitutes of Health, ClinicalTrials.gov [online]. Available from URL: http://www.clinicaltrials.gov [Accessed 2011 May 10]

65. Pfizer Inc. Axitinib (AG-013736) for the treatment of metastatic renal cell cancer [ClinicalTrials.gov identifier NCT00920816]. US National Institutes of Health, Clinical Trials.gov [online]. Available from URL: http://www.cli nicaltrials.gov [Accessed 2011 May 10]

Correspondence: Dr Bernard Escudier, Institut Gustave Roussy, 114 rue Edouard Vaillant, 94805 Villejuif, France. E-mail: Bernard.Escudier@igr.fr 